\title{
СИСТЕМНЫЕ ОСОБЕННОСТИ ПОЛЕЙ МЕХАНИЧЕСКИХ СВОЙСТВ ЛЕНТОЧНЫХ ГЛИН ЭСТОНИИ
}

Инженерными изысканиями за последние два десятилетия накоплен большой фактический материал по основным механическим свойствам ленточных глин Эстонии. Уже в первых обобщающих работах выявлена хорошая зависимость практически всех физико-механических свойств от естественной влажности (Vilo, 1962). C повышением значимости строящихся зданий и сооружений повышаются и требования к изыскательской информации, в том числе и к обобщенным показателям, что заставляет применять довольно сложные статистические методы при обобщении накопленного материала изысканий.

На основе системного анализа геологических тел и статистического моделирования выявлены особенности полей механических свойств ленточных глин Эстонии. Принципиальные положения изучения описаны ранее (Баландин и др., 1982). Надо лишь добавить, что структурная прочность ленточных глин отражена в моделях полей удельного сцепления $(c)$ и угла внутреннего трения $(\varphi)$. Замеры последних получены по методу ускоренного одноплоскостного сдвига (за $1-3$ ч) при относительно небольших (до 50-60 кПа) вертикальных нагрузках, вызывающих уплотнение ненарушенных образцов не более нескольких процентов и соответственно незначительное изменение механических свойств. Определение $\varphi$ и $c$ проведено не совместной обработкой опытных данных по методу наименьших квадратов, а по примененному раньше методу жтрех точек». Особенности сопротивления сдвигу слабых глинистых грунтов, включая ленточные глины, проанализнрованы раньше (Vilo, 1962; Mets, Vilo, 1976). Сжимаемость ленточных глин рассматривается по результатам компрессионных опытов с пробами естественной влажности в диапазоне вертикальных нагрузок 0,050-0,150 МПа.

Изучение физических свойств показало, что плотность и влажность тесно связаны с составом глин, что предопределяет и ряд закономерных особенностей структуры полей сцепления, угла внутреннего трения и модуля деформации, в том числе и характер пространственных вариаций полей, контролирующих физико-механическое состояние ленточных глин, а также подобие математических моделей этого состояния, характеризующих систему и отдельные ее блоки. Вспомним, что в качестве подсистемы рассматривались ленточные глины всей Эстонии, в качестве блоков - отдельные региональные типы их (Баландин и др., 1982).

Данные построения и анализа раснределений замеров полей $c, \varphi$ и $E$ представлены на рис. 1 и в табл. 1. Математическое ожидание полей подсистемы следующее: $c_{\Sigma}-0,011$ МПа, $\varphi_{\Sigma}-20,6^{\circ}, E_{\Sigma}-1,67$ МПа. Преобладающие значения прочности и деформируемости в интервалах двух стандартных отклонений следующие: $c-0,005-0,017 \mathrm{MПа,} \varphi-$ $13,6-27,6^{\circ}, E-0,55-2,80$ МПа при общем размахе распределений $c-0-0,046$ МПа, $\varphi-4-42^{\circ}, E-0,3-10$ МПа (табл. 1). Судя по коэффициентам вариаций $(V)$, наиболее однородным является поле угла внутреннего трения $(V-34 \%)$, наименее однородным - поле показа- 

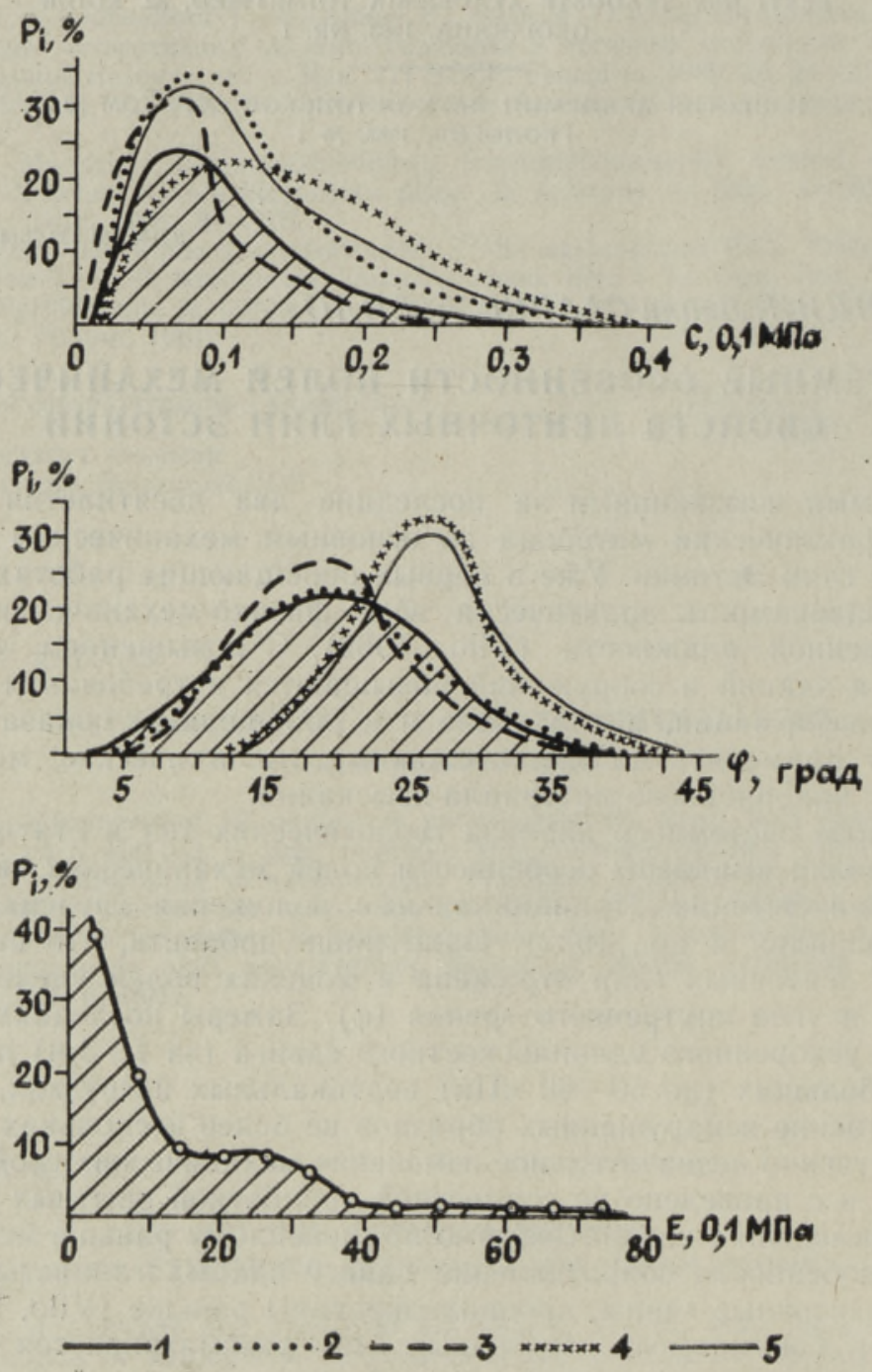

Рис. 1. Графики распределения плотности вероятностей $\left(P_{i}\right)$ удельного сцеплення $(c, 0,1 \mathrm{MПа),} \mathrm{угла} \mathrm{внутреннего} \mathrm{трения}$ (, град) и модуля деформации $(E, 0,1 \mathrm{MПа)}$ ленточных глин Эстонии. Условные обозначения: 1 - ленточные глнны всей Эстонии, 2 - Западной, 3 - Юго-Западной, 4 - Южной, 5 - Восточной Эстоннн.

теля сжимаемости глин $(E-90 \%)$. Поле удельного сцепления характеризуется меньшим, но существенным разбросом значений вариаций $(54 \%)$, что несколько превышает теоретический коэффициент вариации распределения Релея $(46 \%)$. Существенные различия в коэффициентах вариаций отражают разницу в типах распределения плотностей вероятности: для поля $\varphi$ это нормальный гауссовский, для $c-$ нормальный релеевский и для модуля деформаций - анормальный, подчиняющийся закону редких явлений Пуассона (рис. 1).

На основе обобщенных данных прочностных и деформационных свойств изученные отложения можно разделить на две группы: ленточные глины Западной и Юго-Западной Эстонии как менее прочные и ленточные глины Южной и Восточной Эстонии как наиболее прочные. Глины первой группы характеризуются следующими обобщенными значениями: 
Обобщенные показатели механических свойств ленточных глин Эстонии

\begin{tabular}{c|c|c|c|c|c}
\hline Показатель & $\begin{array}{c}\text { Западная } \\
\text { Эстония }\end{array}$ & $\begin{array}{c}\text { Юго-За- } \\
\text { Падная } \\
\text { Эстония }\end{array}$ & $\begin{array}{c}\text { Южная } \\
\text { Эстония }\end{array}$ & $\begin{array}{c}\text { Восточ- } \\
\text { ная } \\
\text { Эстония }\end{array}$ & $\begin{array}{c}\text { Эстония } \\
\text { в целом }\end{array}$ \\
\hline $\begin{array}{c}\text { Сцепление, МПа } \\
\frac{0,012}{0-0,046} 62\end{array}$ & $\frac{0,0078}{0-0,023} 56$ & $\frac{0,0157}{0,002-0,046}$ & $\frac{0,0145}{0,002-0,033} 50$ & $\frac{0,011}{0-0,046} 54$ \\
$\begin{array}{c}\text { Угол внутреннего } \\
\text { трения, град }\end{array}$ & $\frac{19,5}{5-39} 35$ & $\frac{18,1}{4-35} 32$ & $\frac{25,8}{13-40} 21$ & $\frac{24,9}{15-42} 24$ & $\frac{20,6}{4-42} 34$ \\
$\begin{array}{c}\text { Модуль деформа- } \\
\text { цин, МПа }\end{array}$ & $\frac{1,27}{0,3-7,5} 95$ & $\frac{0,96}{0,3-0,4} 73$ & $\frac{3,33}{1,3-7,5} 48$ & $\frac{3,51}{1,3-7,5} 48$ & $\frac{1,67}{0,3-10,0} 90$
\end{tabular}

П р и м е ч а и е. В числителе - матема̀тическое ожидание поля, в знаменателе - размах распределения, справа - коэффициент вариации, \%.

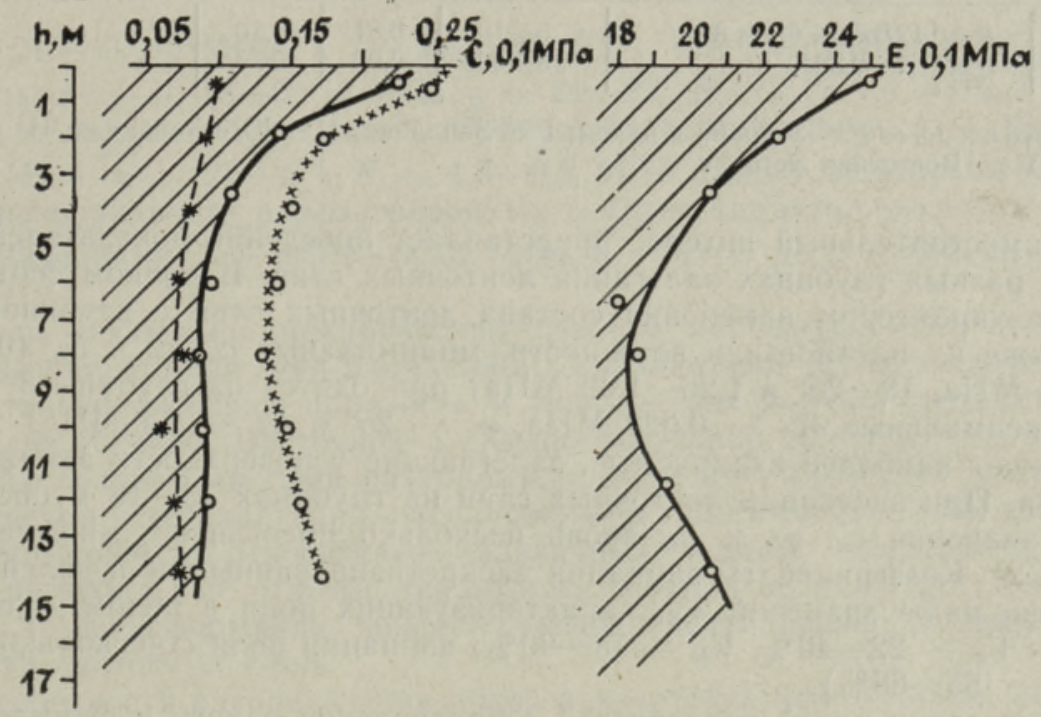

Рис. 2. Обобщенные значения удельного сцепления $(c)$ и модуля деформации $(E)$ для ленточных глин Эстонии, залегающих на различных глубинах от поверхности земли. Условные обозначения см. на рис. 1 .

$\bar{c}-0,012$ и 0,008 МПа, $\vec{\varphi}-19,5$ и $18,1^{\circ}, \bar{E}-1,27$ и 0,96 МПа; глины второй группы соответственно значениями: $\bar{c}-0,016$ и 0,014 МПа, $\bar{\varphi}-26$ и $25^{\circ}, \bar{E}-3,3$ и 3,5 МПа (табл. 1). Аналогичным образом преобладающими значениями рассматриваемых групп ленточных глин являются: $c-0,045-0,020 \mathrm{MПа,} \varphi-12,5-26,5^{\circ}, E-0,34-2,20 \mathrm{MПа}$ (для глин Западной Эстонии); $c-0,012-0,034$ МПа, ф́ $-12-24^{\circ}$, $E-0,26-1,66$ МПа (для глин Юго-Западной Эстонии); $c-0,008-$ $0,024 \mathrm{MПа,} \varphi-20-31^{\circ}, E-1,7-4,9$ МПа (для глин Южной Эстонии); $c-0,007-0,022 \mathrm{MПа,} \varphi-19-31^{\circ}, E-1,8-5,2$ МПа (для глин Восточной Эстонии). В соответствии с этими характеристиками разнятся и коэффициенты вариаций полей $c, \varphi$ и $E$. У первой группы глин они во всех случаях несколько выше общей вариабильности подсистемы в целім $\left(V_{\Sigma}\right)$, у второй - меньше (табл. 1). 
Уравнения зависимостей математических ожиданий сцепления ( $c, 0,1$ МПа), угла внутреннего трения ( $\varphi$, град) и модуля деформации ( $E, 0,1$ МПа) ленточных глин Эстонии

\begin{tabular}{|c|c|c|c|c|c|}
\hline \multirow[b]{2}{*}{ Район } & \multirow[b]{2}{*}{ Уравнение зависимостей } & \multirow{2}{*}{$\begin{array}{l}\text { Интер- } \\
\text { вал } I_{P}\end{array}$} & \multicolumn{2}{|c|}{ Коэффицненты } & \multirow{2}{*}{ Подобие к 1} \\
\hline & & & $\begin{array}{l}\text { ксима- } \\
\text { ции }\end{array}$ & $\begin{array}{l}\text { корре- } \\
\text { ляции }\end{array}$ & \\
\hline $\begin{array}{l}1 \\
\text { I } \\
\text { II } \\
\text { III } \\
\text { IV }\end{array}$ & $\begin{array}{l}C=0,19-0,004 I_{P} \\
C=0,19-0,0032 I_{P} \\
C=0,156-0,0036 I_{P} \\
C=0,195-0,004 I_{P} \\
C=0,185-0,004 I_{P}\end{array}$ & $\begin{array}{r}3-47 \\
13-47 \\
7-37 \\
3-18 \\
3-18\end{array}$ & $\begin{array}{l}0,93 \\
0,88 \\
0,82 \\
0,94 \\
0,91\end{array}$ & $\begin{array}{l}0,76 \\
0,72 \\
0,73 \\
0,77 \\
0,72\end{array}$ & $\begin{array}{l}\text { Явно выражено } \\
\text { Явно выражено } \\
\text { Явно выражено } \\
\text { Совершенное }\end{array}$ \\
\hline $\begin{array}{l}1 \\
\text { I } \\
\text { II } \\
\text { III } \\
\text { IV }\end{array}$ & $\begin{array}{l}\varphi=31,5-0,56 I_{P} \\
\varphi=30,5-0,56 I_{P} \\
\varphi=30,1-0,56 I_{P} \\
\varphi=32,1-0,56 I_{P} \\
\varphi=30,5-0,56 I_{P}\end{array}$ & $\begin{array}{l}3-37 \\
8-35 \\
8-37 \\
3-23 \\
3-18\end{array}$ & $\begin{array}{l}0,90 \\
0,88 \\
0,84 \\
0,89 \\
0,92\end{array}$ & $\begin{array}{l}0,72 \\
0,74 \\
0,66 \\
0,65 \\
0,77\end{array}$ & $\begin{array}{l}\text { Явно выражено } \\
\text { Явно выражено } \\
\text { Явно выражено } \\
\text { Явно выражено }\end{array}$ \\
\hline $\begin{array}{l}1 \\
1\end{array}$ & $\begin{array}{l}E=0,12 I_{P}^{2}-6,0 I_{P}+82 \\
E=17,4-0,32 I_{P}\end{array}$ & $\begin{array}{r}5-18 \\
18-42\end{array}$ & $\begin{array}{l}0,81 \\
0,90\end{array}$ & $\begin{array}{l}0,70 \\
0,75\end{array}$ & \\
\hline
\end{tabular}

П р и м е ч а н и е. 1 - Эстония в целом; I - Западная; II - Юго-Западная; III - Южная; IV - Восточная Эстония.

Самостоятельный интерес представляет поведение показателей $c, \varphi$, $E$ на разных глубинах залегания ленточных глин. В полном соответствии с характером изменения состава ленточных глин с глубиной $(h)$, а также их плотности и влажности, минимальные $c_{h}, \varphi_{h}$ и $E_{h}(0,008-$ $0,009 \mathrm{MПа,} 18-20^{\circ}$ и $1,26-1,30 \mathrm{MПа)} \mathrm{приходятся} \mathrm{на} \mathrm{глубины} 3-10$ м, а максимальные $\left(c_{h}-0,022 \mathrm{MПа,} \varphi_{h}-25^{\circ}\right.$ и $\left.E_{h}-2,4 \mathrm{M \Pi а}\right)$ характеризуют наиболее аэрируемые, залегающие у поверхности земли отложения. При залегании ленточных глин на глубинах 13-18 м обобщенные значения $c_{h}, \varphi_{h}$ и $E_{h}$ вновь несколько превышают минимальные (рис. 2). Коэффициенты вариаций дискретизированных по $h$ полей $\varphi$ и $E$ обычно ниже значений $V_{\Sigma}$, характеризующих поля в целом, и составляют: $V_{\varphi}-22-40 \%, V_{E}-75-90 \%$; вариации поля $c$ несколько выше $\left(V_{c}-55-65 \%\right)$.

Дисперсии полей показателей сопротивления сдвигу и сжимаемости ленточных глин существенно снижаются при дискретизации полей $c, \varphi$ и $E$ по $I_{P}$ (число пластичности). Для этого варианта распределений замеров параметров $V_{c}$ составляют $48-56 \%, V_{\varphi}-22-40 \%$ (в среднем $27 \%$ ) и $V_{E}-50-75 \%$ (в среднем $64 \%$ ).

Модели зависимостей $c, \varphi$ и $E$ от $I_{P}$ представлены в табл. 2 и на рис. 3. Как видно, уравнения связей $c$ и $\varphi$ с $I_{P}$ являются линейными с обратным характером зависимостей для широкого диапазона разновидностей ленточных глин. При этом уравнения, описывающие подсистему в целом и отдельные блоки, оказываются сходными с явно выраженным математическим подобием. Однако зависимости $E$ от $I_{P}$ оказались неоднозначными: для интервалов $I_{P}$, характеризующих супеси и суглинки, зависимость $E=f\left(l_{P}\right)$ является квадратичной параболой, а для глин - линейной (с обратным характером связей).

Для толщ ленточных глин в целом характерными являются следующие обобщенные значения $\bar{c}, \bar{\varphi}$ и $\bar{E}$ : у супесчаных разностей $\bar{c}-$ 0,017 МПа, $\bar{\varphi}-29,5^{\circ}, \quad \bar{E}-5,5$ МПа; у легких суглинков $\bar{c}-0,016-$ 0,015 МПа, $\bar{\varphi}-27-26^{\circ}, \bar{E}-4,2-3,4$ МПа; у средних суглинков 


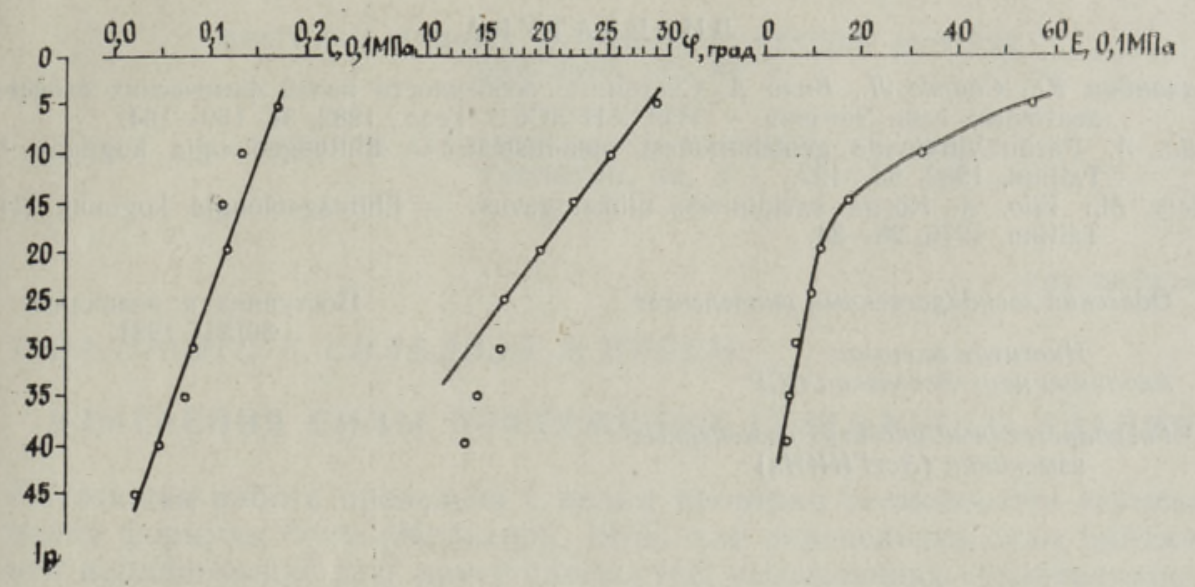

Рис. 3. Зависимость полей удельного сцепления $(c)$, угла внутреннего трения $(\varphi)$ и модуля деформации $(E)$ от числа пластичности $\left(I_{P}\right)$ для ленточных глин

Эстонии.

$\bar{c}-0,015-0,013 \mathrm{MПа,} \bar{\varphi}-26-24^{\circ}, \bar{E}-3,4-2,2$ МПа; у тяжелых суглинков $\bar{c}-0,013-0,012$ МПа, $\bar{\varphi}-24-22^{\circ}, \bar{E}-2,1-1,5$ МПа. Легкие глины обладают следующими обобщенными значениями: $\bar{c}-0,012-$ 0,009 МПа, $\bar{\varphi}-22-17^{\circ}, \bar{E}-1,5-0,9$ МПа. Более дисперсные глинистые разновидности рассматриваемых осадков характеризуются в среднем значениями: $\bar{c}-0,009-0,002 \mathrm{MПа,} \bar{\varphi}-$ от 17 до $8^{\circ}$ и $\bar{E}-$ от 0,9 до 0,3 МПа.

Итак, обобщение механических свойств ленточных глин Эстонии показывает, что для глин Западной и Юго-Западной Эстонии характерна значительно меньшая прочность и повышенная деформируемость, чем для глин Южной, Восточной и Северо-Восточной Эстонии. Эти различия обусловлены многими факторами, прежде всего составом, условиями уплотнения и дегидратации, расположением глин в современном рельефе и экспозицией их отнасительно различных агентов гипергенеза. При этом региональные отличия территории Эстонии не приводят, как правило, к трансформации законов распределения полей механических свойств ленточных глин.

Особенности распределения полей показателей механических свойств ленточных глин по глубинам залегания свидетельствуют о существенной роли в формировании грунтовых параметров этих отложений процессов, контролируемых глубинами. В интервале глубин $0-3$ м постседиментационные гипергенные преобразования отложений определяются почвенно-иллювиальными процессами и 'выветриванием. На глубинах 3-10 м влияние постседиментационных процессов наименьшее, с возрастанием глубины начинаются сказываться и различия в составе (на бо́льшей глубине уменьшается глинистость). На глубинах более 10 м возрастает также уплотняющее давление грунтов кровли, но особенно заметна резко возрастающая роль супесей.

Приведенные обобщенные сведения и уравнения регрессий могут быть полезными в качестве контрольных при решении широкого круга задач инженерно-геологического обоснования проектов зданий и сооружений на ленточных глинах Эстонии. 
Баландин Ю., Саарсе Л., Вило А. Системные особенности полей физических свойств ленточных глин Эстонин. - Изв. АН ЭССР. 'Геол., 1982, 31, 159-164.

Vilo, A. Pärnu viirsavide geotehnilistest omadustest. - Ehitusgeoloogia kogumik I. Tallinn, 1962, 98-127.

Mets, M., Vilo, A. Nõrga savipinnase nihketugevus. - Ehitusgeoloogia kogumik III. Tallinn, 1976, 28-34.

Одесский государственный университет Поступила в редакцию

Ннститут геологии

Академии наук Эстонской ССР

Государственный институт инженерных изысканий (ЭстГИНИз)

J. BALANDIN, Leili SAARSE, A. VILO

\section{EESTI VIIRSAVIDE MEHAANILISTE OMADUSTE VĂLJADE SOSTEEMSED ISEÅRASUSED}

Artiklis on esitatud viirsavide nidususe, sisehõōrdenurga ja deformatsioonimooduli väljade statistilised parameetrid ning korrelatsioon plastsusarvuga nii kogu Eesti kohta kui ka üksikute regioonide kaupa.

\section{Y. BALANDIN, Leili SAARSE, A. VILO}

\section{SYSTEM PECULIARITIES OF MECHANICAL PROPERTIES OF ESTONIAN VARVED CLAYS}

The authors present generalized data, statistical parameters and equations of the dependences of mathematical expectations of shear strength and deformability of Estonian varved clays. Special attention is paid to the spatial change of the fields of shear strength and deformability determined by several factors, including coarse grain-size of clays in the eastern and southern parts of Estonia. These regional differences do not lead to the transformation of the regularities in the distribution of the fields of mechanical properties of the clays studied. 